\title{
An Analysis of Semantic Waves: Maton's Legitimation Code Theory for Cumulative Knowledge-Building
}

\author{
Yolanda Ramadhan \\ Flight Management Vocational High School, Pekanbaru, Indonesia, 28265 \\ yolandaramadhan75@yahoo.com
}

\section{ARTICLE HISTORY \\ Received : 2 May 2019 \\ Revised : 17 May 2019 \\ Accepted : 1 June 2019}

\section{KEYWORDS}

Social Realism

Teaching Theory

Knowledge-Building

Cumulative Training

Semantic Gravity and Density

\begin{abstract}
This paper aims to state that knowledge blindness in educational research has severe obstacles to understanding knowledge development. Karl Maton offers sociological concepts of Legitimation Code Theory (LCT) - 'semantic gravity' and 'semantic density' systematically. These concepts are used to analyse the way the classroom practices of secondary school learning in Indonesia, especially in Biology and History subjects. The researcher shows that the 'semantic wave' class can be a cumulative class practice. The most significant human society in education has the desire to build cumulative knowledge. Researchers usually produce ideas that have usefulness or attraction beyond the specificity of their original context. This research is useful to make the power to explore more indepth knowledge with several policies that state that education must prepare students to live and work in a rapidly changing society by providing knowledge and skills that can develop throughout 'lifelong learning'. Educational learning can also be observed not only by context, but meaning and purpose also affect the cumulative and segmental parts. This problem forms the starting point for interdisciplinary research discussed in the papers collected in this special edition. Freebody (2013). At this point, the problem is the range with each discipline as the background of this research.
\end{abstract}

\section{Introduction}

Karl Maton published an article entitled 'Making Semantic Waves: A key to cumulative knowledge-building on 17 January 2013 Vol 24, which consisted of 22 pages. This paper begins by stating that knowledge in educational research experiences serious obstacles to understanding the development of knowledge. The author said that building this cumulative knowledge allows students to build on previous understanding and transfer what they learn into the context of the future (Hamuddin, 2015). Students can do this exceptionally well as they build knowledge using prior knowledge (Abbas \& Memberti, 2018). This problem forms the starting point for interdisciplinary research discussed in the articles collected in this study.

The researchers also mentioned the opinion of Freebody (2013) outlining some of the main problems that were the background of this research, which specifically focused on teaching in secondary schools. According to researchers, this article offers a way of conceptualizing the development of knowledge in terms of features of knowledge itself. In particular, researchers highlight the importance of 'semantic waves' for cumulative teaching.

This research method publishes ways of conceptualizing the development of knowledge with concepts and models of teaching that can generate ideas for building cumulative knowledge in teaching. The researcher also stated that education must prepare students to live and work in rapidly changing societies by providing knowledge and skills that can build students' knowledge. Overall, there is a prevailing certainty that cumulative learning is the heart of education.

\section{Review of the Article}

The advantage of this article, in my opinion, is that the theory and analysis used is correct so that this article is interesting to read, the language used by the author is simple. It can be understood by the reader so that it is easy to understand. Researchers succeed in making ideas or attraction outside the original context by building knowledge with cumulative concepts about teaching so students can change the way they learn in the future (Derin, Deliani, Fauziah, Afifah, \& Hamuddin, 2019)

The disadvantage of this article is that this article takes too many concepts and models of teaching that are difficult to apply to secondary schools or universities. The researcher writes the results of the wave line from his observations, with that the reader can find out the results of observations of the researcher. In this case, the influence of learning is seeing mental and human psychology. This statement is possible for the learning process and indicators of external influences on increasing knowledge.

The highlights the research results on semantic wave lines include; (a) wave, in terms of the semantic line of the flat line because of the low achievement essay, (b) waves 
moving up and down are needed to build cumulative knowledge, (c) semantic waves do not always start and end at relative height. Ultimately, the semantic wave line becomes a threshold, and this can vary between practice and context. Ongoing research addresses these threshold levels as a matter of nature, such as the relative resolution of epistemological and axiological problems, different in various fields of study and graduation. So, from the results of this research, one of the ambiguous statements in my opinion, which might confuse the reader later.

\section{Method}

This paper used a descriptive qualitative method to describe the knowledge blindness that exists in education research, particularly when it comes to an understanding of the human knowledge department. The theory this paper referred to Karl Maton's Legitimation Code Theory (LCT) because it has quickly become the basis for international and multidisciplinary-based research interest on social justice and knowledge-building (Maton, 2016).

\section{Results \& Discussion}

\subsection{Knowledge-Blindness and Segmental Theorizing}

\subsubsection{In Educational Research}

According to some experts in educational research, knowledge-blindness is characterised as an opinion (Maton, 2013) on the conditions from the current influence of psychology and sociology. According to (Freebody, Maton, \& Martin, 2008) approach to psychological information, usually, focus on the generic process of learning and the differences between the forms of knowledge learned by students.

According to Schwartz, Brophy, Lin, \& Bransford (1999), the construction of the object this research has been supported by the dominance of constructivism, which includes the view of knowledge as a mental process and a condition of consciousness that is within the learner. The background of knowledge education research serves as an object (Bransford \& Schwartz, 1999). Thus, the conclusions of the experts about teaching have oscillated between 'traditional pedagogy' and 'constructivist' which are generalized across curricula, and the development of knowledge as unclear content or skills such as 'critical thinking'.

\subsubsection{Segmental Theorizing of Knowledge}

Seeing the prevalence of knowledge-blindness doesn't mean there is no model of knowledge. Several experts, including Bourdieu, Foucault, and Piaget, have distinguished daily knowledge from an unreasonable common sense of education or education. There are several models of knowledge into view as objects of study. Seeing the second obstacle, most models embody segmental forms that theorize. The conclusions of several experts, namely all experts, agree that there is a need to change the teaching model for the future according to the semantic wave.

\subsection{Legitimation Code Theory: Semantics}

Legitimacy Code Theory (LCT) is a sociological tool for practical studies. Cumulatively the LCT works in the code theory approach that is used to expand real conceptual tools (Blackie, 2014; Jackson, 2016). LCT is a functional work unit that is used to explore several problems, practices, and contexts (Clarence, 2016). For example, Arbaugh, Fornaciari, \& Hwang (2016) have used LCT to identify research topic development.

\subsubsection{Semantics}

LCT has a semantic dimension that builds social fields of practice as semantic structures that have organizational principles that are conceptualized as semantic codes, which are two parts of semantic gravitational strength and semantic density. Judging from some of the concepts of semantic gravity may be relatively stronger.

\subsubsection{Semantic Profiles}

Looking back on the obstacles to exploring knowledge development, the concept of semantic gravity and semantic density is overcome by the knowledge-blindness and segmental theorem. Researchers carry the underlying principles of characteristics by looking at the strength of mathematical gravity, and semantic density may vary, resulting in semantic code $(\mathrm{SG}+/-, \mathrm{SD}+/-)$. In other words, 'semantic gravity' and 'semantic density' are not multiple categories.

Semantic codes give data serving how the semantic concept in some part. This part was discussed by crucial for capturing knowledge-building, a practice enacted through time. Conceptualizing processes of strengthening and weakening semantic gravity and semantic density

\subsubsection{In Simplicity}

Judging from the discussion of existing concepts, so far only the necessary discussion of definitions that are not definitive at all. As discussed in this article, research that uses these concepts quickly reveals their fecundity and complexity. This concept shows that the wave is not a state of monotony. Waves have signed up and down indicators based on semantic points. So, that wave is related to semantics and knowledge. 


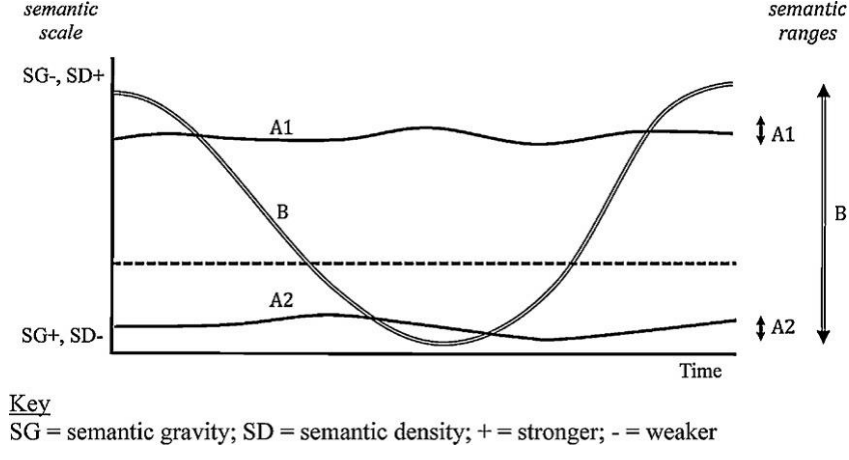

Figure 4.2.3.1 Illustrative Semantic Profiles and Semantic Ranges

\subsection{Teaching in Modelling Semantic Waves}

The Knowledge and School Discipline Project (DISKS) utilizes LCT and systemic functional linguistics (SFL) as a complementary framework for exploring cumulative teaching in secondary schools. The method used in this test is by taking video. There are three dimensions of LCT that are reflected in the project

\subsubsection{Down Escalators and High Stakes}

In this section, the focus is on what can be described as 'high stakes' in school learning and teaching. On the other hand, institutional knowledge that must be learned usually manifested in written forms such as textbooks or source documents and learned by reading, on the other hand, the knowledge students must show for their assessment, namely in writing assignments. It is useful to know the success of mastering pedagogical subjects in students. However, the position on the semantic scale was relatively lower than the last, varied low but increased from the initial years to the next study year.

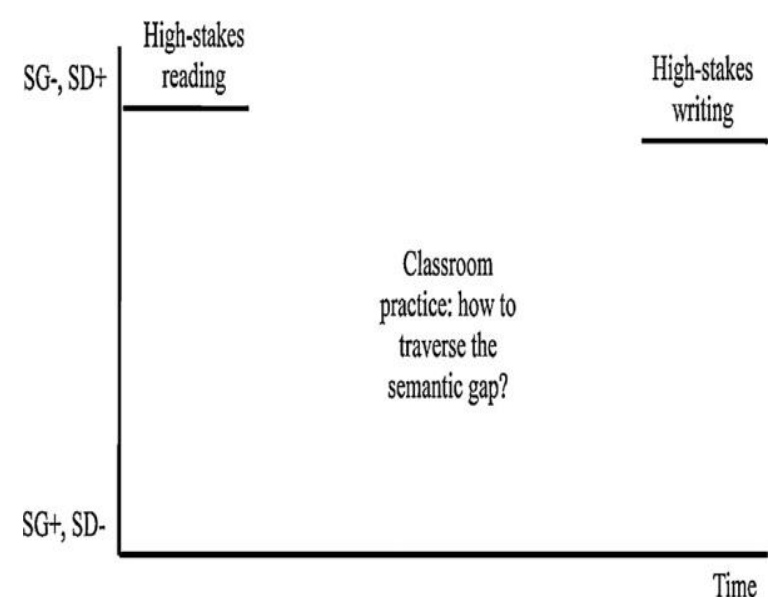

Figure 4.3.1.1 The High Stakes of Learning and Teaching

In the picture above, there are several shifts in the semantic of (SG-, SD +) concluding a simple understanding with $\left(\mathrm{SG}+, \mathrm{SG}_{-}\right)$. This escalator decline often makes problems so the teacher must repeat reading and be serious to understand. Thus, the movements in the profile model are often backward and segmented.

The profile is a lesson that means academic that has potential problems to build up the cumulative knowledge. The knowledge that is characterized by relatively weak semantic density and relatively strong gravity semantics can link certain contexts to future or past knowledge.

\subsection{Depth of Semantic Waves}

After seeing the concept of LCT on the previous page, here are examples of semantic waves in section 4 that look more concrete and simple. The author analysed the semantic profile by the lecture method. The author also discusses how research looks at semantic waves becoming complicated and broad. From a strong point of view, research concludes that semantic waves seem to go beyond the classroom and interact with practice very rapidly. Theoretically, semantic profile analysis can develop so widely that it can embrace and realize the social agenda of justice.

\subsubsection{Profile in the Classroom}

Substantive learning mentions increasingly developed forms and roles of code. As all research starts from pedagogy, curriculum and assessment, this study shows that the use of the DISKS project raises tentative expectations for a while. In the middle school classroom, the value of the pedagogical approach does not depend on specific advice.

The published learning and the application of semantic profile analysis are increasingly widespread so that the practice in knowledge is different. Researchers suggest that whatever the field remains important for building knowledge over time and requires an upward shift from specific meanings and contexts.

The lesson shows that the use of the DISKS project can give rise to some tentative guesses that are cumulative pedagogical practices in high school classrooms, semantic profiles can be high. Students can excel if in class, discuss three theoretical texts with abstract ideas. Semantic waves can publish new ideas and literary cultures that have their characteristics. The value cannot depend on specific suggestions that have been localized. Lessons that are broadcast can show broader results in applying analysis to semantic profiles. To understand the importance of a strong and cumulative semantic profile, it can be seen from the different practices and theories made in theory and methodology.

The researcher suggest that re-contextualisation in knowledge and whatever its fields still have an important role to play in building knowledge over time (Luckett, 2010). To make an upward shift from specific Meaning and context, need to do small waves to move. In an educational study on an approach that often tracks high flat lines can reflect the abstract discussion of concise concepts that only involve a little empirical data. The data can be described 
and can be limited from other context lessons. Cumulative theory can be made in a specific context in substantive studies that concretize and only involve a part of the meaning that has existed or been phrased again.

\subsubsection{Embracing a Variety of Complexity Profiles}

In the wave of the semantic shift from top to bottom, it can lead to a simple shift. Still, it can also be translated to increase the semantic threshold as the concept of analysing non-homogeneous semantic waves. For research, researchers suggest making a question what profile you want to use along with its purpose and in what context is made. This semantic field is related to biology, biologically the respiratory system with digestion is included in the semantic/influential wave inside the semantic threshold.

Lessons in the diversity of profiles and semantic concepts can explore various kinds of thresholds that range in semantic waves. However, they are limited in nature and viewed from a flat line can allow the threshold to be problematic because of its low achievement essays. The problem of relative emphasis is on different epistemological and axiological learning with cross-field material that goes through the stages of education. The threshold that looks for accuracy can vary between contexts and practices.

In the field of learning to build this systematic wave, it can provide high enthusiasm for high school and high school students. Research in physics studies shows that students can achieve the semantic scale in their work by understanding the concepts and objectives of what they make.

Principles that are too abstract and generalize with more meaning as their duty to make them understand. Semantic shifts can play different roles in various fields. The rise and fall of the semantic scale can be emphasized in response to the frequency of escalators in the lessons analysed for DISKS. Building cumulative knowledge can increase broad insight and can develop ideas for further development such as employment for various scholars.

Semantic waves are the key to the development of cumulative studies by activating recontextualization of knowledge through time and space. But there are things that emphasize that semantic waves may take many forms from answers to everything wave. Moreover, the concept of semantic bidding is very useful in a learning process. Working with a subject specialist can build mastery of knowledge. That is why DISK can join or be involved with History and Biology teachers.

With this graph, students can easily find results from what they are doing. According to the process, if they are right to do it, the results will also be true; otherwise, if they are wrong, then the results will be wrong too. It all depends on the way the students work.

\subsubsection{Dimensions and Principles Included in the Semantics}

This lesson shows the emergence of semantic waves in various institutional contexts and disciplines that do not negate the difference between practice and theory. Examples of practices in the fields of production, recontextualization, and reproduction cannot be equated with one another because they have different logic.

Thus, Humalog semantics, research, learning and practice have no problems at all. Students need to be contextualized in knowledge in the semantic field of gravity. So, even though the profile is similar, the waves on the semantic scale might also change.

In addition, semantic code has several scales, and the scale is not the only underlying wave. For example, similar semantic profiles might repeat across different subject areas along other dimensions. In DISKS projects knowledge is revealed in lessons in Biology and History offering semantic profiles that are similar but fundamentally different.

The concept of Specialization, the second dimension reveals that Biology lessons embody a code of knowledge in which legitimacy emphasizes epistemic relations with the object of study and History lessons which are realized with codes that know better where legitimacy emphasizes social relations with actors. For example, from several studies, this specialization code has a different effect on educational practice. Thus the semantic concept can form part of its multi-dimensional toolkit to explore semantic complexity. This dimension can also be integrated.

In some parts for semantic gravity and semantic density, some parts can be taken in various forms that can be analysed using other concepts or concepts that exist. For example, to use Specialization on various forms of semantic density is seen in the third part of the image. The technical epistemological condensation has other conceptual meanings, such as those in the example of 'aesthetic trade' and 'cilia' class. This meaning is a form that the author applies to this paper.

However, other studies also highlight semantic densities involving ethics, politics, moral attitudes, and emotions. For example in the field of education the attitude that research must have in relation to student-centred learning is usually in politics and attitudes.

\subsubsection{Building Integration of Social and Semantic Justice}

While semantic profiles provide knowledge of organizing principles, this principle is confidential. Not everyone has the same ability to treat shifts in semantics aimed at achieving the desired achievement. As the example illustrated on the page above, it can be seen that not all students can control the semantic profile and it is complicated for students to recognize that this semantic 
profile or wave is an important aspect or means to realize a semantic profile. Some actors entering the structure or design on the semantic profile cannot recognize it either. In this application, it requires excellent knowledge and concentration to get satisfactory results.

There are several practices described by Bourdieu, namely a meeting between two developing histories, which is contained in the disposition of actors and context logic or code. To restore the knowledge of social realist vocation in educational research which emphasizes a lesson that uses a multidimensional LCT toolkit that is usually used to explore the attributes of knowledge applied in social practice.

The code has become the main focus in practice. However, overcoming a knowledge-blindness is difficult and very difficult but does not need to give up on blindness. Because there are several parts that will later help overcome the problem of knowledge-blindness. Thus, LCT can also be used to analyse the dispositions brought by actors in the apprenticeship context of education based on their experience. There are several kinds of pre-existing research traditions that use systemic sociological and functional linguistic codes that explore the orientation of social distribution and the encoding of actors that are in them.

In LCT terms, there is a semantic range that is greater than the capacity to achieve higher on the semantic scale which starts from concrete meaning, simple to very abstract condensed, and not evenly distributed. Further research is needed to explore both the coding orientation of different people and their relationship to the code that dominates the context of education. For example, for a while DISKS, projects tentatively think that cumulative teaching involves modelling semantic waves and waves such as larger ranges and can be smaller. In pedagogic practice, it does not guarantee all students to experience this cumulative learning.

The concept of the LCT framework can change the semantic tools of the students themselves to become more developed. These chain concepts start from the semantic range, from abstract meanings, generalizations, very concrete, specific and certainly more straightforward in its application. More learning describing how the LCT framework works, it is easier to solve a problem in a study or study.

These concepts give rise to an analysis of various events that appear to be different from being united in view of their different uniformities. To pass spaces in the semantic space between concepts and various data and practices, a lot of learning can develop a new discovery. Thus the practice of this research can realize what is learned from semantic waves as a bridge to build a broad knowledge.

However, in the concepts that were applied earlier, there were those that provided the means to unite knowledge analysis to reveal more ways for students to obtain legitimate code keys. And students need not be afraid or anxious if there are some students who cannot participate in cumulative learning.

\section{Conclusion}

In conclusion, this study takes the form of many semantic waves that have been published by other publishers, so this article is less complex to reveal cumulative knowledge. However, this researcher seeks to develop and realize what is learned from semantic waves as waves that build knowledge about cumulative teaching to students. This meaning has provided a concept to advance the way of learning with semantic gravity. This meaning has also provided a way to build work structures in substantive learning. This method is applied well to secondary schools because here it also trains student discipline and ways to focus on teaching in secondary schools, researchers also get research results in the form of semantic wave modelling in teaching, first by collecting data, analysing both teaching texts that are the third is the pedagogic intervention in which teachers are trained to be involved in construction together with students to teach linguistic resources in education. So this article is worth recommending.

\section{Acknowledgement}

The research author extends her gratitude to the Applied Linguistics Center for their aid in the discussions that took place during the conception of this article.

\section{References}

Abbas, M. F., \& Memberti, D. (2018). Using Friendliness, Language, Interest, and Prior Knowledge (Flip) Strategy to Improve Students' Reading Comprehension in Narrative Text. ELT-Lectura, 5(2).

Arbaugh, J. B., Fornaciari, C. J., \& Hwang, A. (2016). Identifying research topic development in business and management education research using legitimation code theory. Journal of Management Education, 40(6), 654-691.

Blackie, M. A. (2014). Creating semantic waves: Using Legitimation Code Theory as a tool to aid the teaching of chemistry. Chemistry Education Research and Practice, 15(4), 462-469.

Bransford, J. D., \& Schwartz, D. L. (1999). Rethinking transfer: A simple proposal with multiple implications. Review of Research in Education, 24, 61-100.

Clarence, S. (2016). Exploring the nature of disciplinary teaching and learning using Legitimation Code Theory Semantics. Teaching in higher education, 21(2), 123-137. 
Derin, T., Deliani, S., Fauziah, N., Afifah, N., \& Hamuddin, B. (2019). Indonesians' Tendency to Refer Abbreviation as Acronym: Types of Abbreviation as Word Formation Process. Globish: An EnglishIndonesian Journal for English, Education, and Culture, 8(2).

Freebody, P. (2013). Knowledge and school talk: Intellectual accommodations to literacy?. Linguistics and Education, 24(1), 4-7.

Freebody, P., Maton, K., \& Martin, J. R. (2008). Talk, text, and knowledge in cumulative, integrated learning: A response to'intellectual challenge'. Australian Journal of Language and Literacy, The, 31(2), 188.

Hamuddin, B. (2015). Bringing EA into ELT's Classroom: Rising Students' Awareness to Avoid Errors. ELTLectura, 2(2).

Jackson, F. (2016). Unraveling high school English literature pedagogic practices: a Legitimation Code Theory analysis. Language and education, 30(6), 536-553.

Luckett, K. (2010). Knowledge claims and codes of legitimation: Implications for curriculum recontextualisation in South African higher education. Africanus, 40(1), 4-18.

Maton, K. (2013). Making semantic waves: A key to cumulative knowledge-building. Linguistics and education, 24(1), 8-22.

Schwartz, D. L., Brophy, S., Lin, X., \& Bransford, J. D. (1999). Software for managing complex learning: Examples from an educational psychology course. Educational Technology Research and Development, 47(2), 39-59. 